\title{
Die Entwicklung der katholischen Publizistik im 20. Jahrhundert historische Positionen und internationale Aspekte
}

\author{
von Michael Schmolke
}

$\mathrm{Zu}$ jenen gesellschaftlichen Veränderungen, die im 20. Jahrhundert das Wirken der Kirche in wesentlichen Punkten berührt haben, gehören die Entwicklungen auf dem Gebiet der Massenkommunikation. Zwar standen Kirche und Publizistik immer in gewissen Beziehungen zueinander, und die kritische Auseinandersetzung mit der sich emanzipierenden Presse hat bereits in den ersten Jahrzehnten des 19. Jahrhunderts (z. B. unter Gregor XVI.) eingesetzt ${ }^{1}$. Jedoch brachte erst das 20. Jahrhundert die volle Entfaltung jener "Instrumente der sozialen Kommunikation" - so seit 1963 der vatikanische Sprachgebrauch —, die unter dem Begriff der Massenmedien, auch Massenkommunikationsmittel, zusammengefaßt werden: zur modernen Presse (in ihren Erscheinungsformen als informierende und meinungsbildende Tages- und Wochenpresse mit hoher Verbreitung, Unterhaltungspresse und Fachpresse) traten Film, Hörfunk und Fernsehen. Deren technische Entfaltung - wie überhaupt die Industrialisierung der publizistischen Produktion - provozierten auch die Entwicklung neuer Träger öffentlich-kommunikativer Angebote, die neue Märkte entstehen ließen: Schallplatte, Tonband, Schmalfilm, neuerdings Bildplatte und, nicht $\mathrm{zu}$ vergessen, das den Buchmarkt verändernde Taschenbuch.

Im wesentlichen sah bzw. sieht sich die Kirche seit der Jahrhundertwende fünf massenkommunikativ wichtigen Erscheinungen und Entwidklungen gegenüber, mit denen sie sich auseinandersetzen muß; denn Veränderungen in den Massenkommunikationssystemen einzelner Völker, ganzer Kulturkreise und in einzelnen Fällen sogar der "Weltgesellschaft", betreffen das Wirken der Kirche, insbesondere in ihrem Verkündigungs- und in ihrem pastoralen Auftrag. Diese fünf Punkte sind: (1) der Rückgang, in manchen Ländern das Verschwinden der "Gesinnungspresse“, (2) die neuen, sogenannten audiovisuellen Medien Film, Hörfunk und Fernsehen, (3) der Griff totalitärer politischer Systeme nach den publizistischen Einrichtungen in verschiedenen Staaten, (4) die völlig neuen Aufgaben und Chancen, die sich für den Einsatz von Kommunikationsmitteln in Entwicklungsländern ergeben, und (5) die Desintegration des "katholischen Publikums“ in Ländern bzw. Kulturkreisen, wo dieser Begriff von der praktischen Publizistik ${ }^{2}$, aber auch der Pastoral, Jahrzehnte lang mit einiger Berechtigung hatte gebraucht werden können. Als sechster Punkt, der aber nicht als Gegenüber der Kirche, sondern aus ihr heraus, als Reaktion auf dieses publizistische Gegenüber, entstanden ist, verdient die organisatorische wie (neuerdings) theoretische Auseinandersetzung der Kirche mit der Massenkommunikation besondere Beachtung.

So nützlich diese Kategorien zur Analyse unseres Themas sind, so sind sie doch, schon aufgrund ihrer unterschiedlichen zeitlichen Dimensionen, nicht alle zur historischen Gliederung des Gegenstandes geeignet; als Aspekte der neuen Problemstellungen werden sie in verschiedenen Abschnitten auftauchen.

Bei diesem Beitrag unseres Mitherausgebers handelt es sich um den Vorabdruck eines Teilkapitels (Die Kirche und die Massenmedien) aus dem demnächst im Verlag Herder (Freiburg/Br.) erscheinenden Schlußband (Bd. VII) des "Handbuchs der Kirchengeschichte“. Den Herausgebern dieses Werkes, den Professoren Hubert Jedin und Konrad Repgen (beide Bonn), dankt CS für die Genehmigung zum Vorabdruck. 


\section{Der katbolische Anspruch und die "farblose Presse“}

War die katholische Publizistik-Diskussion des 19. Jahrhunderts vorwiegend vom Kampf gegen die "schlechte Presse“ („mauvaise presse“, „stampa perversa“, „stampa negativa") bestimmt, so brachte das beginnende 20. Jahrhundert einen neuen Feind, - richtiger: die Erkenntnis, daß da, neben der „schlechten “, d. h. liberalen, sozialistischen, gelegentlich auch protestantischen Presse eine neue Erscheinungsform der Zeitung entstanden war: die "farblose Presse". Die katholische Presse - als die einzige „gute Presse" - wurde $\mathrm{zwar}$ von vielen katholischen Kritikern nur als das kleinere Übel respektiert ${ }^{3}$, aber sie hatte doch gerade im letzten Drittel des ausgehenden Jahrhunderts einige bemerkenswerte Anfangserfolge erzielt. Stolz auf Gründungen wie "De Tijd“ (1846), „Kölnische Blätter“ (1860; ab 1869 „Kölnische Volkszeitung"), "Germania“ (1871) oder „La Croix“ (ab 1883 als Tageszeitung), übersah man eine Zeit lang, daß inzwischen ein neuer Zeitungstyp entstanden war: die Nachrichtenzeitung (presse d'information), die im Unterschied zum klassischen Typ des 19. Jahrhunderts, der "Gesinnungszeitung", auf Parteibindung oder eindeutige weltanschauliche Festlegungen verzichtete. Katholische Presse hingegen war nur als Gesinnungspresse vorstellbar; auch die zahlreichen kleinen Blättchen, die während des Kulturkampfes die katholische Zeitungsgründungskurve hochschnellen ließen ${ }^{4}$ oder wenig später als Gründungen lokaler oder regionaler "Preßvereine" besonders in Bayern und Osterreich ${ }^{5}$ für weiteres Wachstum sorgten, waren trotz ihres Lokalblattcharakters Gesinnungszeitungen. In den Vereinigten Staaten (1833 „The Sun“, 1835 „The New York Herald"), Frankreich (1836 „La Presse" und „Le Siècle") und England (1855 "Daily Telegraph and Courier") waren längst Zeitungen "für alle" entstanden, die, um ein möglichst breites Publikum zu erreichen, nicht nur die Verkaufspreise senkten, sondern auch auf Parteilichkeit verzichteten ${ }^{8}$. In Deutschland erschienen (ab 1871) die ersten Zeitungen dieses Typs gelegentlich unter Verwendung des Titels oder Titelbestandteils "Generalanzeiger“. Dieser Begriff wurde bald mit einem abwertenden Beiklang versehen. Der Generalanzeigerpresse fehlte es an Gesinnungstüchtigkeit, - eben dies machte ihre "Farblosigkeit" aus. Die Tatsache, daß die "farblose Presse" verlegerisch erfolgreich war, daß - im Hinblick auf die Auflagen - erst mit ihr das Zeitalter der Massenpresse begann, machte sie nur noch verdächtiger.

Die Generalanzeiger waren die „schlechte Presse“ neuen Typs, die in Deutschland seit 1889 auf den katholischen Generalversammlungen regelmäßig verdammt werden:

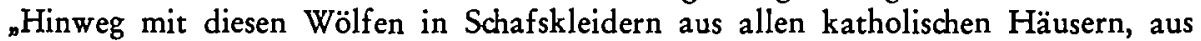
allen katholischen Familien, aus allen katholischen Gemeinden!" (Ernst Lieber, 1895) Autoren wie Joseph Eberle, Viktor Kolb, später Felix Hardt und eine Legion von Kleinschriften kämpften gegen Aufweichungstendenzen. Besonders typisch für diese Phase der "Presseapostel " sind die Bücher Joseph Eberles (Großmacht Presse ${ }^{7}$ ) und Giuseppe Chiaudanos (Il Giornalismo Cattolico ${ }^{8}$ ). Während Eberle in erster Linie die allgemeine (nichtkatholische) Presse denunziert, verdeutlicht Chiaudano, was alles die katholische Presse nicht darf, was sie sich aber, z. B. in der Diskussion von dubia oder in der Kritik kirchlicher Entscheidungen, nördlich der Alpen längst herausgenommen hatte - im Widerspruch zu des Jesuitenpaters Erläuterungen über "necessità dello spirito di disciplina e di obbedienza“. Auch der Codex Iuris Canonici faßt im Titel XXIII Zensur- und Verbotsregeln zusammen, die bei strikter Befolgung den Katholiken eine normale Beteiligung an der Publizistik ihrer Zeit (aktiv und passiv) fast unmöglich gemacht hätten. Wo sie, als Verleger, Journalisten und Leser an der gesellschaftlichen Kommunikation teilnahmen, konnten sie dies, wenn 
sie gewissenhaft waren, nie ganz ohne schlechtes Gewissen tun. Das gebrochene Verhältnis der Kirche zur Publizistik war noch keineswegs überwunden, als das Zeitalter der "neuen Medien“ begann.

\section{Film und Hörfunk in der Frühphase}

Kurz vor der Jahrhundertwende wurden Filmvorführungen (zunächst als VarietéAttraktionen), ab 1920 wurde der Hörfunk öffentlichkeitsreif. Die Frühgeschichte der kirchlichen Auseinandersetzung mit diesen neuen Medien ist noch kaum erforscht. $\mathrm{Als}$ sicher kann gelten, daß man sie als publizistisches Medium von allgemeiner gesellschaftspolitscher Relevanz zunächst nicht erkannt hat. Volksbildung und Kunst waren die Bereiche, denen man "den Kino" (so der erste Sprachgebrauch) und das Radio zuwies. Unter dem Stichwort „Bildungsaufgaben“" wandte man ihnen, jedenfalls in Mitteleuropa, recht früh besondere Aufmerksamkeit zu. Während in den Vereinigten Staaten, die sich schnell zum Mutterland der Film-Großindustrie entwidkelten, die kirchliche Aufmerksamkeit sich stärker auf die Auswüchse von Spielfilminhalten richtete, kritisierte man z. B. auf den Generalversammlungen der Katholiken Deutschlands zwar auch die "vergiftenden Auswüchse des Kinos", bekannte sich jedoch in "Kino-Reform-Anträgen" zum Ziel der "positiven Reformarbeit" (Aachen 1912). Es ist heute fast vergessen, daß schon 1910 im Rahmen des Volksvereins für das katholische Deutschland in Mönchengladbach die "Lichtbilderei GmbH" gegründet wurde, die Diapositiv-Serien und bald auch Lehrfilme beschaffte, verlieh bzw. samt den dazu notwendigen Geräten vertrieb. Eine Schriftenreihe („Lichtbühnen-Bibliothek“) und die Fachzeitschrift „Bild und Film“ (ab 1912) ergänzten das Angebot, bis der Erste Weltkrieg diesen konstruktiven Bemühungen zunächst ein Ende setzte ${ }^{\theta}$. Nach dem Krieg wurden sowohl die Filmarbeit als auch die anfänglich in freien Initiativen betriebene katholische Rundfunkarbeit in besonderen Arbeitskreisen im 1919 gegründeten Zentralbildungsausschuß der katholischen Verbände Deutschlands (ZBA) angesiedelt.

Freilich hatten sowohl ZBA als auch die Fuldaer Bischofskonferenz zunächst gezögert, als sich nach dem offiziellen Beginn öffentlicher Rundfunksendungen in Deutschland (Oktober 1923) Möglichkeiten für kirchliche Mitwirkung bei der Gestaltung von Sendungen ergaben. Sorge machte die Übertragung gottesdienstlicher Handlungen ein bis heute nicht ausdiskutiertes Problem -, während der Zugang unter den Titeln Kunst und Volksbildung weniger problematisch war $^{10}$. Risikof reudiger gab man sich beim Film: Mit eigenen Produktionsfirmen („Leo-Film“, München 1927, und „Eidophon “, Berlin) sollte ein katholischer Anteil zum Spielfilmangebot beigesteuert werden. Der Erfolg blieb aus, und die Leo-Film-A.G. zog 1933 das Münchener Leohaus (Hauptstelle katholisch-sozialer Vereine) in den Konkurs. Filmarbeit als Bildungsaufgabe und zunehmend auch als Aufgabe einer bewahrenden Pastoral konnte sich jedoch konsolidieren. Das amerikanische Beispiel der 1933 gegründeten Legion of Decency und ihr wachsender Einfluß auf die amerikanische Filmproduktion machten starken Eindruck. Auch die Mitwirkung beim Hörfunk etablierte sich auf Dauer. Zwar gelang es nicht, wie in den Niederlanden, in Spanien oder Portugal eigene Rundfunksysteme oder Programmbetriebsgesellschaften einzurichten. Die intensive Mitarbeit jedoch, die besonders vom Rundfunk-Prälaten Bernhard Marschall („Die Katholiken haben beim Rundfunk von Anfang an mitgearbeitet"11) vorangetrieben wurde, sicherte trotz der bald darauf einsetzenden nationalsozialistischen Rundfunkgleichschaltung den Mitwirkungsplatz der Kirche. 
Einen gewissen Abschluß fand diese erste Phase der kirchlichen Befassung mit Film und Rundfunk in der Gründung internationaler Organisationen: Im April 1928 wurde in Den Haag das Office Catholique International du Cinéma (OCIC) gegründet, und ebenfalls 1928 entstand, im Anschluß an die Kölner internationale Presseausstellung „Pressa“, das Bureau International de la Radiophonie Catholique (nach dem Zweiten Weltkrieg: „Unda“). Erster Leiter des Büros wurde Bernhard Marschall, so wie zuvor schon Leo-Film-Direktor Georg Ernst die Präsidentschaft des OCIC übernommen hatte ${ }^{12}$. Auf dem Gebiet des Films wirkte jedoch in den Folgejahren das amerikanische Vorbild der Legion of Decency maßstabsetzend, d. h. die auf "moral codes" aufbauende, eher auf zensurähnliche Bewahrungspastoral hinauslaufende Praxis setzte sich durch. Sie fand den Respekt der amerikanischen Filmproduzenten ${ }^{13}$ und den Beifall des Papstes: Pius XI. sah sich durch die Arbeit der Legion zur Film-Enzyklika "Vigilanti cura" (1936) veranlaßt ${ }^{14}$ : Künftig sollten in allen Ländern moralisch wertende Film-Listen geführt und den Gläubigen nahegebracht werden.

\section{Die Entwicklung der katholischen Presse im internationalen Uberblick}

Wenn von „katholischer Presse“ die Rede ist, ergeben sich regelmäßig Definitionsschwierigkeiten. Sie entstehen einerseits aus der Tatsache, daß katholische Presse nicht unbedingt kirchliche Presse sein muß, und andererseits aus der Frage nach den Kriterien, nach denen sich nicht-kirchliche, aber dennoch katholische Presse als katholisch bestimmen lassen soll. In unserem Zusammenhang wird „katholische Presse" dann für gegeben angenommen, wenn mindestens eines der folgenden vier Merkmale anzutreffen ist: (1.) Nennung (z. B. im Titel oder Untertitel: „Katholische Zeitung für...", „Bistumsblatt..."), (2.) Bindung (an kirchliche Amtsträger und/oder Einrichtungen, auch an katholische Vereine, Bewegungen, Parteien), (3.) aktive konfessionelle Bindung der Person oder des Gremiums der Herausgeberschaft/Chefredaktion und (4.) eindeutig erkennbare inhaltliche Schwerpunktsetzung ${ }^{15}$.

Die Entstehung einer profiliert katholischen Presse scheint durch bestimmte Sozialstrukturen gefördert, durch andere behindert zu werden: Extreme Diasporasituationen lassen, wie die Beispiele Englands oder der skandinavischen Länder zeigen, katholische Periodika nur marginal aufkommen; aber auch traditionell rein katholische Gesellschaften, womöglich nodh mit Staatskirchencharakter der katholischen Konfession, sind der Profilierung nicht unbedingt förderlich (z. B. Spanien, Italien). Dies ändert sich in dem Moment, wo starke laizistische oder kirchenfeindliche Bewegungen aufkommen (z. B. Frankreich, neuerdings Polen). Förderlich wirken sich aus die Existenz annähernd gleich starker, großer Konfessionsgruppen, die Polarisierung in tonangebende christliche bzw. sozialistische oder liberale Parteien oder auch die konfessionelle „Versäulung“ einer pluralistischen Gesellschaft; insofern sind etwa Deutschland, Osterreich, die Schweiz und die Niederlande klassische katholische Presseländer, und auch die USA haben ein vielfältiges katholisches Pressewesen hervorgebracht. Wachsender Wohlstand und umfangreiche, vielfältige sowie politisch unbehinderte Versorgung mit Kommunikationsangeboten scheinen die konfessionelle Presse (wie übrigens auch die Parteipresse) zu schwächen, während kommunikationspolitischer Druck (Presselenkung, Gleichschaltung), sofern er konfessionelle Publizistik nicht gänzlich beseitigt, die übriggelassenen Organe konsolidiert. Die hier erwähnten Bedingungen haben die Geschichte der katholischen Presse im 20. Jahrhundert 
bestimmt, - naturgemäß verschieden in den verschiedenen gesellschaftlichen und politischen Ordnungen. Für die deutschsprachigen Länder Europas und die Niederlande hat sich dabei insofern eine ähnliche Entwicklung ergeben, als die katholische Presse mehrheitlich an katholische bzw. christliche Parteien heranrückte bzw. diese Parteien unterstützte, ohne daß es dabei, von Ausnahmen abgesehen, zur strikt geregelten Parteiorganschaft (wie etwa bei kommunistischen und sozialdemokratischen Parteien sowie bei der NSDAP) kam. Die Parteinähe hat sich vor dem Ersten Weltkrieg entwickelt, während seit dem Ende des Zweiten Weltkriegs eine zunehmende Distanzierung erkennbar wird.

In Deutschland wurden katholische Presse und Zentrumspresse bis 1933 - trotz mannigfacher Differenzierungsdiskussionen - de facto gleichgesetzt. Aus dem Kulturkampf hervorgegangen, erreichte diese Presse den quantitativen Höhepunkt ihrer Entfaltung kurz vor dem Ersten Weltkrieg. Die Statistik des 1878 gegründeten "St. Augustinusvereins zur Pflege der katholischen Presse" nennt für 1912446 "katholische Zeitungen“" und eine Gesamt-Abonnentenzahl von 2,625 Millionen ${ }^{16}$. Die Titelzahl sank zwar nach dem Krieg nicht nennenswert (1931: 434), allerdings hatten schon Konzentrationsvorgänge stattgefunden, so daß längst nicht mehr von 434 selbständigen Zeitungen die Rede sein konnte; die Auflage wurde damals auf 2,5 Millionen geschätz $\mathrm{t}^{17}$. (Eine zuverlässige und in den Kategorien einheitliche Statistik der katholischen Presse in Deutschland - und auch sonst in der Welt - gibt es nicht ${ }^{18}$.)

Die allgemein übliche Zuordnung zur Zentrumspartei ließ die katholische Tagespresse nach der national-sozialistischen Machtergreifung 1933, spätestens nach der Selbstauflösung des Zentrums, in die nationalsozialistische Presselenkungskategorie der „bürgerlichen" Presse fallen. Das bedeutete lediglich, daß sie nicht sofort - wie die Presse der KPD und SPD (mittels der Verordnung zum „Schutz von Volk und Staat vom 28. Februar 1933) - beseitigt wurde. Das Goebbelswort vom 4. Oktober 1933 („Der Vielgestaltigkeit der öffentlichen Meinungsbildung ist durchaus kein Hindernis entgegengesetzt. " ${ }^{18}$ ) sicherte den "bürgerlichen " Zeitungen keinerlei Freiraum. Die (ex-)katholischen unter ihnen waren, wenn auch direkte Verbote zunächst selten waren, allen Gleichschaltungsmaßnahmen der nationalsozialistischen Pressepolitik ausgesetzt. Spektakulär abgewürgt wurde 1934/35 die „Rhein-Mainische Volkszeitung ", die sich in den letzten Jahren der Weimarer Republik neben "Germania" und "Kölnischer Volkszeitung" ein überregionales Profil fortschrittlich-katholischer Prägung erworben hatte. Manche Blätter, wie die 1848er-Gründung „Deutsches Volksblatt" oder der "Badische Beobachter" (Karlsruhe), fanden keinen Weg, sich den Einschnürungen immer neuer pressepolitischer Verordnungen zu entziehen und gaben (1935) auf ${ }^{20}$. Andere, wie die ausgerechnet 1932 in eine wirtschaftliche Existenzkrise geratene "Kölnische Volkszeitung " oder die "Germania", konnten überleben, wobei die rechtskatholische Linie der "Germania" (Nähe zu Hitlers erstem Vizekanzler Franz von Papen) nicht immer den Beifall ihres Publikums fand: nicht im wörtlichen Sinne unterdrückt, sondern von den eigenen Lesern verlassen, stellte sie am 31. Dezember 1938 ihr Erscheinen ein ${ }^{21}$. Die übrige, meist kleinere Tagespresse war vielfältigen Konzentrationsprozessen ausgesetzt, die meist durch nationalsozialistische Maßnahmen befördert wurden. Deren Ziel war das Einbringen möglichst vieler ehemals katholischer Blätter in eine der nationalsozialistischen Auffang-Verlagsgesellschaften; auf katholische Objekte spezialisierten sich die Vera-Verlagsanstalt GmbH und die Phönix-GmbH. An sie mußte unter Zwang verkauft werden, wenn z. B. ein Verleger wegen Ausschluß aus der $Z$ wangs-Standesorganisation der Reichspressekammer nicht mehr Verleger sein durfte ${ }^{22}$. 
In der gleichen Reichspressekammer konnte sich hingegen die katholische Zeitschriftenpresse als „Fachschaft katholisch-kirchliche Presse" beinahe etwas wie ein Reservat schaffen; bis 1936 gewährte es, u. a. unter Ausnutzung des unklaren Konkordatsbegriffs der „amtlichen Diözesanblätter" (als der einzigen in den Schutz des Reichskonkordats von 1933 einbezogenen Pressegattung), relativ weitreichenden, nach 1936 noch einigen Schutz. Unter dem politischen Druck stiegen bis 1936 Titelzahl und Gesamtauflage (von 9,6 auf 11,4 Millionen zwischen 1933 und 1936). Erst 1936 setzten jene Maßnahmen ein, die - vor der allgemeinen Papiersperre von 1941 fast drei Viertel der 416 Titel von 1936 verschwinden ließen, die aber auch den seither die Struktur der katholischen Presse in Deutschland und Osterreich bestimmenden Typ des "Bistumsblatts" erzwangen: Je Diözese sollte es nur mehr ein, vom Bischof $\mathrm{zu}$ bestimmendes und zu autorisierendes Bistumsblatt geben ${ }^{23}$. Auch für die katholische Presse in vielen anderen Ländern Europas bedeutete der Zweite Weltkrieg einen deutlich markierenden Einschnitt. Für Deutschland und wenig später für Osterreich setzte er früher ein als für die Niederlande, Belgien, Polen oder Frankreich. In all diesen Ländern zeigten die beiden Jahrzehnte zwischen 1920 und 1940 die katholische Presse in einer gewissen Stabilität, allerdings eher zur Konzentration als zur Expansion tendierend. Einen Uberblick, schon im Schatten der sich anbahnenden Katastrophe, bot die "Weltausstellung der katholischen Presse", die vom 12. Mai 1936 bis zum 31. Mai 1937 unter starker internationaler Beteiligung (63 Aussteller, meistens Länder oder Ländergruppen aus allen Kontinenten) in der Vatikanstadt stattfand. Der Berichtband ${ }^{24}$ ist nicht nur eine der wenigen umfassenden Quellen für den Stand der katholischen Presse in den dreißiger Jahren, er läßt auch die europäische Situation erkennen: Deutschland ist mit ganzen zweieinhalb Druckseiten vertreten (Frankreich: 34), aus denen man einige historische Titel, die Auflage der "Germania" (7.500), aber auch Daten über den „Völkischen Beobachter", den „SA-Mann" und den „Schulungsbrief" erfährt, während sich Italien und Ósterreich zwar knapp, aber doch mit Auflistungen ihrer noch umfangreichen Bestände vorstellen dürfen, obwohl der Berichtband erst 1939 erschien.

In Osterreich hatte schon 1912 die 1894 gegründete christlich-soziale "Reichspost" das konservativ-katholische "Vaterland“ (1860-1911) aus dem Felde geschlagen. Sie blieb auch nach dem Ersten Weltkrieg die führende katholische Stimme, den Ständestaat gutheißend, antimarxistisch, aber auch kritisch gegen „Anschluß“-Pläne, deren gewaltsame Verwirklichung 1938 das Ende der seit 1902 von Friedrich Funder geleiteten Zeitung bedeutete ${ }^{25}$. Die katholische Presse der österreichischen Länder konnte sich auf die gegen Ende des 19. Jahrhunderts allenthalben gegründeten ${ }_{n}$ Katholischen Preßvereine“ stützen. Deren Tradition erwies sich auch nach dem Ende des Zweiten Weltkriegs als so stark, daß die aus ihnen hervorgegangenen, meist mittelgroßen Verlagsunternehmen das Fundament sowohl der neuen Bistumsblätter als auch jener Zeitungen abgeben konnten, die christlich orientiert sind und die Osterreichische Volkspartei unterstützen.

In Wien hat es ein Anknüpfen an die katholische Tageszeitungstradition der „Reichspost" nach 1945 nicht gegeben; die Wochenzeitung „Die Furche" verstand sich als Traditionsträger. Neben dem Innsbrucker „Volksboten“ (seit 1973: „präsent“) vertritt sie den Typ der Wochenzeitung für die intellektuelle katholische Leserschaft. Die führende Kulturzeitschrift "Wort und Wahrheit" (gegr. 1946) wurde 1973 eingestellt.

Die katholische Presse in der Schweiz geht mit einigen wichtigen Organen auf die gleiche Zeitspanne zurüdk, da in Deutschland der Kulturkampf die Entstehung katho- 
lischer Blätter provozierte: „La Liberté (Freiburg) und das „Vaterland“ (Luzern) wurden 1871 gegründet, das „Basler Volksblatt“ 1872 und „Die Ostschweiz" (St. Gallen) 1874. „Die katholische Bevölkerung scheint ein Bedürfnis nach eigenen Standortblättern verspürt zu haben, mit denen sie sich wie mit den Verbänden politisch-religiös identifizieren konnte, ja, die wesentlich zur Definition ihrer Identität in der schweizerischen Gesellschaft beitrugen. ${ }^{\text {“2 }}$ Die jüngste Gründung, die „Neuen Zürcher Nachrichten" (1896 als Vereinsblatt, 1904 Tageszeitung) entwickelte sich zwar nicht zur Konkurrenz der "Neuen Zürcher Zeitung“, aber doch zur bekanntesten katholischen Großstadtzeitung der Schweiz, während das „Vaterland“ als „Konservatives Zentralorgan für die deutsche Schweiz" bis in die Gegenwart hinein nicht nur meinungsbildend, sondern auch wirtschaftlich stabilisierend wirkt. Denn auch die Schweizer Presse versucht ihre Existenz durch Konzentrationsmaßnahmen zu sichern, die neuerdings $\mathrm{zu}$ intensiver Kooperation mit den ruhenden Polen „Vaterland" und „Ostschweiz" geführt und auch in der Zeitschriftenpresse manche Veränderungen bewirkt haben.

Lediglich in einigen wichtigen Zeitschriftengründungen hat die Aktivität der englischen Katholiken ihren publizistischen Ausdruck gefunden: "The Tablet" (gegr. 1840), „The Universe“ (1860), der "Catholic Herald“ (1884) und die 1864 von Jesuiten gegründete Zeitschrift "The Month" blicken auf beachtliche Traditionen zurück. Frankreich hingegen zählt nach wie vor zu den wichtigen katholischen Presseländern. Die zahlund konfliktreichen publizistischen Aktivitäten des 19. Jahrhunderts ${ }^{27}$ fanden einen abschließenden Höhepunkt in der Etablierung der Maison de la Bonne Presse durch die Assumptionisten, insbesondere durch Vincent de Paul Bailly. Jenes katholische Publizistik-Zentrum in der Pariser Rue Bayard, das die "gute Presse" programmatisch in die Firmenbezeichnung aufnahm, ging aus der Gründung $z$ weier Periodika hervor, die dann über Jahrzehnte hin wesentliche Stimmen der katholischen Publizistik Frankreichs waren: 1872/73 begann Bailly mit „Le Pellerin“, gegründet ursprünglich als monatliches Organ des Conseil Général des Pèlerinages, 1877 jedoch umgewandelt zu einer volkstümlichen bebilderten Zeitschrift, die wenig später die Auflagenschwelle der 100.000 überschritt. 1880 trat unter dem Titel „La Croix" eine Monatszeitschrift hinzu; 1883 in eine Tageszeitung umgewandelt, entwickelte sich „La Croix" zum "quotidien catholique par excellence ${ }^{\text {238. }}$. Der Gründungsphase nach vergleichbar mit der "Germania" oder dem Luzerner „Vaterland", erwies sich jedoch „La Croix" als eine auch quantitativ erfolgreiche Zeitung; in ihren ersten Jahrzehnten volkstümlich, überschritt sie noch im Gründungsjahrzehnt die 100.000-Auflage, erreichte noch vor dem Ersten Weltkrieg 185.000 (1912) und soll 1937 ihr Rekordjahr mit einer Auflage von 300.000 (unkontrolliert) gehabt haben. Das sind Zahlen, die der katholischen Tagespresse in Deutschland unerreichbar blieben. Im $Z$ weiten Weltkrieg wich "La Croix" zunächst nach Bordeaux, dann nach Limoges aus. Da sie erst am 21. Juni 1944 ihr Erscheinen unterbrach, mußte sie nach der Befreiung Frankreichs ein Wiederzulassungsverfahren durchlaufen, das die Startbedingungen verschlechterte. Die Nachkriegsauflage bewegte sich um 100.000, stieg erst wieder durch den Anschluß der 1889 gegründeten „La Croix du Nord“ (Lille) im Jahre 1959. Das Zweite Vaticanum ließ das Interesse noch einmal wachsen (Auflage ca. 140.000), aber der Gewinn des Blattes, das nach seinem Selbstverständnis den Maßstäben eines „journal d'opinion“ wie eines „journal d'information“ entsprechen will, ließ sich nicht halten. Die Ausgabe "La Croix du Nord" wurde 1968 auf wöchentliches Erscheinen reduziert. Die katholische Tagespresse Frankreichs schrumpfte zwischen 1958 und 1964 von neun auf vier selbständige Blätter (darunter nur "La Croix“ von Bedeutung), die Zeit- 
schriftenpresse jedoch lebt von der reichen Vielfalt, zu der sie sich im 19. Jahrhundert und im ersten Drittel des 20. Jahrhunderts entfaltet hatte. Mitte der 1960er Jahre glaubte man, nach Abzug der Pfarrblätter, noch von rund 1.000 Titeln sprechen zu dürfen ${ }^{29}$. Die neben der Bonne Presse wichtigsten Verlage sind die Union des Oeuvres Catholiques de France (gegründet 1871) und (seit 1945) der Verlag der Illustrierten "La Vie [Catholique Illustrée]", die neben "Le Pèlerin (du 20e Siècle)" Mitte der sechziger Jahre eine Halb-Millionen-Auflage erreichte. Die Sonntagspresse ist in der Kette der verschiedenen „Croix-Dimanche"-Ausgaben (1964 in 15 Departements), begonnen 1889 unter dem Titel „La Croix du Dimanche“ (Politische Beilage zum "Pèlerin"), stark vertreten. Besondere Aufmerksamkeit widmeten die katholischen Verlage Frankreichs schon früh der Kinder- und Jugendpresse. Einige Titel, wie "Nade" (1914) oder "Record" (Vorläufer "L'Echo du Noël“, 1906) gehen auf die Zeit vor dem 1. Weltkrieg zurück. Lange hielt sich eine ziemlich hohe Zahl von Titeln bei kleineren Auflagen. Die überregionale Wochenpresse mit intellektuellem Anspruch ließ über lange Zeit, ähnlich wie vergleichbare Medien in Deutschland, eine Flügelbildung erkennen: „La France Catholique“ (gegründet 1925) wurde als konservativ, "Témoignage Chrétien“ (1941) als progressiv eingestuft, beide Auflagen schwanken um 50.000 (1968).

Die Entwicklung der katholischen Presse Frankreichs vollzog sich im großen ganzen in Unabhängigkeit von der Amtskirche. Die ,in struktureller Hinsicht ... unabhängige katholische Presse" (Ehlinger) ist seit 1951 bzw. 1952 in zwei Verbänden zusammengefaßt, der Association Nationale des Périodiques Catholiques de Province (ANPCP) und dem Centre National Catholique de Presse (CNPC). „Die Eintragung einer Zeitschrift oder Zeitung in einen dieser Verbände gilt als klares Kennzeichen der Zugehörigkeit dieser Veröffentlichungen zur katholischen Presse. ${ }^{{ }^{430}}$

In Spanien „wäre es nicht falsch, die Behauptung aufzustellen, daß alle Tageszeitungen, die heute ... erscheinen, in gewisser Weise sich als katholisch betrachten. Doch nicht alle verdienen diese Bezeichnung zu Recht." "31 Das Problem der katholischen Presse nach dem Ende des Bürgerkriegs war es, sich unter einer offiziell kirchenfreundlichen Regierung in einem nicht freiheitlich-demokratischen System so einzurichten, daß ein spezifisch katholisches Profil wieder erkennbar werden konnte. Das Pressegesetz vom 22. April 1938 ließ wenig Spielraum dafür, und das neue, großzügigere Pressegesetz vom 18. März 1966 wurde 1968 einschränkend verändert. Katholische Profilierung wurde auf drei Wegen versucht: (1) bei der Tagespresse durch Zusammenarbeit in Gruppen, von denen die Editorial Católica und die Zeitungsgruppe des Opus Dei je für sich an zweiter bzw. dritter Stelle hinter der Cadena del Movimiento sich placieren konnten. In der Editorial Católica erscheint mit "Ya" (Madrid, gegründet 1935, Auflage 1968: 140.000) eine der drei großen Tageszeitungen des Landes; (2) bei den Zeitschriften durch mehr oder minder deutlich oppositionelle Haltung, die (z. B. im Falle von „Signo“, 1967) bis zum Existenzrisiko gehen kann; (3) in der Journalistenausbildung, der von katholischer Seite besondere Aufmerksamkeit geschenkt wird. International beachtenswert und in Spanien nicht nur staatlich anerkannt, sondern inzwischen maßstabsetzend, ist der Studiengang Journalistik an der 1958 als Institut für Journalismus gegründeten Facultad de Ciencias de la Información der (Opus-Dei-)Universität von Navarra in Pamplona ${ }^{32}$.

Die Entwicklung der katholischen Presse Italiens war bis ins 20. Jahrhundert hinein von den Auseinandersetzungen zwischen dem italienischen Staat und dem Kirchen- 
staat bestimmt. Uber Jahrzehnte hin konnte die national gesinnte liberale Presse sicher sein, mit der öffentlichen Meinung konform zu gehen. Die katholische Presse des rein katholischen Landes befand sich hingegen politisch von Anfang an in der Verteidigungsstellung. „L'Osservatore Romano“ begann am 1. Juli 1861 als „giornale politico-morale ${ }^{\alpha}$ zu erscheinen; für ihn, der zwar unter Kontrolle und mit Förderung des kirchenstaatlichen Innenministeriums, aber anfangs doch nach außen hin als (neben dem offiziellen "Giornale di Roma“, 1849-1870) quasi private politische Zeitung auftrat, galt noch nicht das Montini-Wort: „Non per nulla, come se dice, è ,il giornale del Papa'.“ Zweck des neuen Blattes war Abwehr: „,die Verleumdungen zu entlarven' und, wie man später hinzufügte, ,zu widerlegen, die man gegen Rom und den römischen Pontifikat schleudert'.. ${ }^{\text {ss }}$ In der Zeit zwischen 1870 und 1929 erschien der $O$. R. als politische Tageszeitung, neben anderen römischen Zeitungen, aber doch in einer besonderen Entwicklung, wie es in einem Beitrag der ersten als Erscheinungsort die Città del Vaticano ausweisenden Nummer vom 4./5. November 1929 heißt: „Unter dem Pontifikat Leos XIII. nahm der ,Osservatore Romano“ immer mehr den Charakter eines Organs des Heiligen Stuhls an ... ${ }^{\text {жs }}$

Auch die nächstfolgenden 15 Jahre sahen den O.R. wie die übrige katholische Presse Italiens in schwieriger Position. Unmittelbare Eingriffe gab es jedoch erst nach dem Eintritt Italiens in den Zweiten Weltkrieg. Zu gelegentlichen Vertriebsverboten für Italien ( $\mathrm{Zu}$ viele Leser hat jetzt [Anfang 1940] die katholische Zeitung der Vatikanstadt, die aufmerksam überwacht werden müssen!"35) trat ab 13. Juni 1940 die Unterdrückung der O. R.-Gepflogenheit, die Wehrmachtberichte der kriegführenden Mächte abzudrucken. Dennodh soll die Auflage in den Kriegsjahren auf mehr als 300.000 Exemplare gestiegen sein.

Nach dem Zweiten Weltkrieg hat sich der O. R., „offiziell, soweit es die vom Vatikan stammenden Meldungen betrifft, und offiziös für den Rest ${ }^{\text {"s6 }}$, so entwickelt, daß er zwiespältige Beurteilung provoziert: einerseits z. B. von "The Times" als zur „Weltpresse $^{\alpha}$ gehörig apostrophiert ${ }^{37}$, wird er andererseits gerade von katholischen Journalisten wegen der vielfältigen Abhängigkeiten seiner Redakteure und wegen seiner wenig journalistik-gerechten Arbeit kritisiert. Angesichts der kargen Arbeitsbedingungen ist jedoch die trotz bescheidener Auflage (ca. 70.000) der Stamm-Ausgabe zielstrebige internationale Expansion beachtlich. Außer dem illustrierten Schwesterblatt „L'Osservatore della Domenica" (seit 1934, wöchentlich) wurde 1951 eine lateinamerikanische Wochenausgabe in Buenos Aires ins Leben gerufen. Seit 1948 gibt es eine italienische Edizione settimanale, seit 1949 eine französische, seit 1968 eine englische, seit 1969 eine spanische, seit 1970 eine portugiesische und seit 1971 die „Wochenausgabe in deutscher Sprache" ${ }^{\text {"38. }}$.

Im übrigen ist die katholische Presse Italiens, vergleichbar der in anderen Ländern Westeuropas, nach dem Zweiten Weltkrieg zunehmendem Konzentrationsdruck unterworfen ${ }^{38}$. Von ihren nicht sehr zahlreichen Tageszeitungen ${ }^{40}$ mußte sich im Dezember 1968 der traditionsreiche Bologneser „L'Avvenire d'Italia“ (gegründet 1896) aus wirtschaftlichen Gründen, aber auch wegen zu progressiver Haltung, mit der Mailänder „L'Italia“ (gegründet 1912) unter neuem Titel („Avvenire“) zusammenschließen. - Vom Ausland zunächst kaum beachtet, entwickelte sich in Italien seit 1931 eine katholische Unterhaltungszeitschrift zum vermutlich auflagenstärksten katholischen Periodikum der Welt: die „Famiglia Cristiana“. Gründer, Eigentümer und Verleger ist die auf dem Gebiet der katholischen Publizistik international tätige Religiosengemeinschaft ,Pia Società San Paoloc. Durch ein geschickt organisiertes Ver- 
triebssystem in den Pfarreien ließ sich das einstige Sonntagsblättchen zu einer modernen Familien-Illustrierten ausweiten, die ihre Jubiläums-Ausgabe zum 40jährigen Bestehen in einer $Z$ wei-Millionen-Auflage druckte ${ }^{41}$. Im Verhältnis dazu ist die diözesane Wochenpresse trotz hoher Titelzahl (mehr als 100) unterentwickelt. Innerhalb der Unione Cattòlica Stampa Italiana (UCSI) hat sie sich in einer eigenen Gruppe, der Federazione Italiana Settimanali Cattolici (FISC), zusammengeschlossen.

Auflösung katholischer publizistischer Vereinigungen scheint hingegen in jenem Land eine entscheidende Wende zu markieren, das man als das soziologisch und sozialgeschichtlich ergiebigste Feld katholischer Pressegeschichtsforschung beschreiben könnte: in den Niederlanden. Die Vereinigung Katholieke Nederlandse Dagbladpers und der Katholieke Nederlandse Journalisten-Kring, beide auf Wunsch des Episkopats 1945 bzw. 1946 (wieder)errichtet, stellten ihre Tätigkeit 1968/69 ein. Katholische Journalisten und auch ihr Publikum wurden spätestens seit dem Zweiten Vaticanum der "Versäulung" als der besonderen Ausdrudksform des Pluralismus in den Niederlanden überdrüssig" ${ }^{42}$. Von der seit dem apologetisch-kämpferischen 19. Jahrhundert stets relativ starken katholischen Tagespresse (1937: 32 katholische Tageszeitungen unter insgesamt 79) erwies sich jenes Blatt als das lebenskräftigste, das sich nach dem Zweiten Weltkrieg als journal d'information mit politisch-katholischem Kurs von sozial orientierter Progressivität profilierte, ohne die Katholizität besonders herauszukehren: „De Volkskrant“ (Amsterdam) konnte seine Auflage von 150.000 (1947) auf 206.000 (1974) steigern, und auch eine katholisch orientierte Lokalpresse hielt beachtliche Auflagenanteile. Andere Organe hingegen, die den „versäulten“ niederländischen Katholizismus der 1920 er und 1930 er Jahre mitgeprägt hatten, so "De Maasbode“ (1868-1959) oder „Het Centrum“ (1884-1960), fusionierten oder verschwanden ganz, und die Traditionsträgerin der katholischen Presse, „De Tijd“ (1842-1974), siechte nach dem $Z$ weiten Weltkrieg dem Ende entgegen, auch als sie sich bewußt für die Forumsfunktion zwischen den katholischen Fronten entschieden hatte ${ }^{43}$. Insgesamt blieb der Anteil der mindestens an katholische Traditionen anknüpfenden Presse in den Niederlanden recht hoch. Ahnliches gilt für das benachbarte Belgien, dessen Katholiken noch früher eine stabile politische und publizistische Position errichteten. Die Spaltung in eine konservative und eine christlich-demokratische Richtung kurz vor der Jahrhundertwende ähnelt österreichischen Vorgängen. Unter den großen Blättern Belgiens konnten sich katholische Titel in französischer ("La Libre Belgique", seit 1883) wie in niederländischer Sprache ("De Standaard“, seit 1914) gute Positionen bewahren (Auflagen 1968: 170.000 bzw. 290.000) ${ }^{44}$. Einmalig, allenfalls dem "Osservatore Romano ${ }^{*}$ vergleichbar, ist die Rolle, die das "Iuxemburger Wort" im kleinsten Benelux-Staat spielt: größte Zeitung des Landes mit ungebrochener Tradition seit 1848 und stabiler Auflage (73.000) ${ }^{45}$.

Während sich also in den meisten im Zusammenhang mit katholischer Presse nennenswerten Ländern Europas auch katholische Tageszeitungen in gewissem Umfang über den Zweiten Weltkrieg hinaus erhalten konnten, bedeutete dieser Einschnitt für Deutschland (und für jene Länder, die fortan als sozialistische zählten, darunter das katholische Polen) cum grano salis das Ende der katholischen Tagespresse. Die Lizenzpolitik der alliierten Besatzungsmächte und die Gründung der bewußt überkonfessionell agierenden Christlich-Demokratischen Union verhinderten Wiederoder Neugründungen ${ }^{46}$. Nur eine Zeitung wurde noch einem katholischen Traditionsträger der Weimarer Zeit, Johann Wilhelm Naumann, lizenziert: die ${ }_{n}$ Augsburger Tagespost" (28. August 1948), aus welcher die überregionale, aber auflagenschwache 
(unter 30.000) "Deutsche Tagespost" streng konservativ-katholischer Observanz hervorging. Als nach Aufhebung des Lizenzzwangs (September 1949) die „Alt-Verleger" Traditionstitel oder deren Fortsetzungen wiederzugründen bemüht waren, engagierten sich auch einige katholische Verlage. Die meisten dieser Gründungen verschwanden jedoch wieder vom Markt, unter ihnen das "Deutsche Volksblatt" (Stuttgart 1848, mit Unterbrechung in der NS-Zeit, bis 1965), die „Badische Volkszeitung “ (Karlsruhe, Einstellung 1969), das „Bamberger Volksblatt“ (Einstellung 1969), die „Trierer Landeszeitung ${ }^{\prime} /$ Saarbrücker Landeszeitung“ (Einstellung 1972).

Schnell und stabil wieder-, zum Teil neu gegründet wurden 22 Bistumsblätter in den Westzonen und zwei („St. Hedwigsblatt“, Ost-Berlin, „Tag des Herrn“, Leipzig) in der Sowjetischen Besatzungszone. Neben ihnen entstand (im Westen) eine reich entfaltete Verbands-, Jugend- und Ordenspresse. (Verlage und Redaktionen schlossen sich 1949 in der Arbeitsgemeinschaft Katholische Presse e. V. [früher Arbeitsgemeinschaft Kirchliche Presse; AKP], katholische Publizisten aller Medien 1948 in der Gesellschaft katholischer Publizisten Deutschlands e. V. zusammen.) Unterhaltungszeitschriften konnten sich nur bescheiden entwickeln, Kulturzeitschriften unterlagen, mit Ausnahme der „Stimmen der Zeit", einem Entkonfessionalisierungssog („Werkhefte", „Frankfurter Hefte", „[Neues] Hochland"); politische Wochenzeitungen schließlich sahen sich einer quantitativ nicht ausreichenden Zielgruppe gegenüber und konnten existenzsichernde Auflagenschwellen nicht überschreiten. Selbst die über Jahre stabile Auflage (zwischen 50.000 und 60.000 pendelnd) des als katholisch und CDU-nahe geltenden, tatsächlich aber politisch wie verlegerisch unabhängigen ${ }_{n}$ Rheinischen Merkur" (Köln/Koblenz, gegründet 1946) reichte bei steigenden Produktionskosten nicht aus, die wirtschaftliche Unabhängigkeit zu erhalten; 1974 ging das Blatt mehrheitlich in kirchliches Eigentum über. Das politisch ehrgeizige, aber weniger erfolgreiche "Echo der Zeit" (Recklinghausen, 1952 hervorgegangen aus dem Kölner "Katholischen Beobachter" ${ }^{\text {") wurde }} 1968$ zugunsten des anspruchsvollsten Experiments eingestellt, das die katholische Kirche in der Bundesrepublik Deutschland nach dem Zweiten Weltkrieg unternommen hat: 1968 wurde nach fast dreijährigen Vorbereitungsarbeiten die Wochenzeitung „Publik “ (Frankfurt/Main) gegründet. Nach ihrer differenziert ausgearbeiteten Programmatik sollte sie die führende Stimme des deutschen Katholizismus und zugleich das Forum der gerade in der Zeit nach dem Konzil weit auseinanderstrebenden Meinungspositionen sein. Weil sich mit diesem Konzept kein hinreichend großer und stabiler Abonnentenstamm gewinnen ließ, wurde „Publik “ im Herbst 1971 eingestellt, nachdem es Gesamtkosten von (mindestens) 30 Millionen DM verursacht hatte ${ }^{47}$. Damals hatte die katholische Presse den Höhepunkt ihrer Nachkriegsentwicklung - 1963 sprach man (ohne zuverlässige Basis) von 400 Titeln und einer Gesamtauflage von 16 Millionen - längst hinter sich gelassen. Die 22 Bistumsblätter (1963: Gesamtauflage 2,45 Millionen) verloren, von einigen Ausnahmen abgesehen, Jahr für Jahr bestimmte Anteile ihrer Leserschaft (1974: knapp unter der 2-Millionen-Grenze) ${ }^{48}$. Die katholische Jugendpresse verkümmerte ${ }^{48}$. Während die erste nachkonziliare Phase in Deutschland allgemein den Eindrudk einer geistig erstarkenden Kirche entstehen ließ, begann der Rückgang des publizistischen Potentials Sorge zu bereiten ${ }^{50}$.

Die Informationen über die katholische Presse in der DDR und in den östlichen Nachbarländern flossen in der gesamten Nachkriegszeit spärlich. In der $D D R$ blieb man auf die beiden erwähnten Kirchenblätter und die nicht-periodischen Publikationen des Leipziger St. Benno-Verlags beschränkt. Das tschechische Blatt „Katolicke 
Noviny", in einer tschechischen und einer slowakischen Ausgabe erscheinend, galt stets als der regierungsfreundlichen Priesterbewegung „Pacem in terris" nahestehend, während in Polen das Wochenblatt "Tygodnik Powszechny" (Krakau, gegründet 1945) im Rahmen der Znak-Gruppe (und mit ihm einige Bistumsblätter sowie die Warschauer Monatsschrift "Wiez") relative Unabhängigkeit bewahren konnten, konkurrierend mit der Pax-Gruppe und deren Organ "Slowo Powszechne". Im sozialistischen Jugoslawien setzte sich die 1962 im Zusammenhang mit dem Zweiten Vaticanum gegriindete Zeitschrift "Glas Concila" unerwartet schnell durch: Die auf 180.000 steigende Auflage verursachte jedoch eine besonders aufmerksame politische Uberwachung, die zahlreiche Verbote und Beschlagnahmungen im Gefolge hatte.

\section{Katholische Nachrichten-Agenturen}

Ein Bedürfnis, die katholische Presse mit Hilfe besonderer Zuliefer-Institutionen, der Presse- oder Nachrichten-Agenturen, mit speziellem Informationsmaterial zu versorgen, wurde schon vor der Jahrhundertwende erkannt. Aus ihm ging in Deutschland die katholisch-politischen Zwecken dienende Gründung (1879) der Centrums-Parlaments-Correspondenz (CPC) hervor, eine Initiative nicht der Zentrumspartei, sondern des Augustinusvereins zur Pflege der katholischen Presse. Sie und ihre NachfolgeEinrichtungen (CPC-GmbH, ZPK-GmbH) versorgten katholische Zeitungen mehr schlecht als recht mit Informationen aus den parlamentarischen Aktivitäten des Zentrums, - bis zur Auflösung der ZPK im Jahre 192251.

Katholische Presseagenturen im eigentlichen Sinne entstanden jedoch erst im Ersten Weltkrieg: 1917 in Freiburg/Schweiz die KIPA (Katholische Internationale PresseAgentur); ebenfalls auf 1917 geht der amerikanische NC-News-Service (Washington) zurück. Er erwuchs aus der Presseabteilung des 1917 ins Leben gerufenen National Catholic War Council (NCWC, später = National Catholic Welfare Conference, heute United States Catholic Conference) ${ }^{52}$. Die dritte (für katholische Verhältnisse) "große" Agentur ist die 1952 aus den Vorläufern KND und CND hervorgegangene KNA (Katholische Nachrichtenagentur, Bonn/München) ${ }^{33}$. Sie hat neben ihrem aktuellen Dienst einen ganzen Fächer von Spezialdiensten entwickelt, verfügt über ein europäisches und überseeisches Korrespondentennetz und war eine der treibenden Kräfte bei der mit dem Zweiten Vatikanischen Konzil in Rom beginnenden Zusammenarbeit katholischer Nachrichtenagenturen: 1971 hat sie in einer Internationalen Union katholischer Nachrichtenagenturen eine feste Form gefunden, in welcher KNA, KIPA, Kathpress (Osterreich), CIP (Belgien) und KNP (Niederlande) ${ }^{54}$ eine gemeinsame Redaktion unter der Bezeichnung CIC (Centrum Informationis Catholicum) betreiben. Als eigentliche offiziös römische Agentur galt lange Zeit der 1927 im Zusammenhang mit der Propaganda Fide gegründete "International Fides Service ${ }^{\text {c5s }}$, der jedoch zunehmend an Bedeutung verlor, als seit dem $Z_{\text {weiten }}$ Vaticanum die Pressearbeit des Vatikans in der "Sala Stampa" konzentriert und intensiviert wurde.

1936 gab es in 16 Ländern der Erde katholische Agenturen oder ähnliche Einrichtungen, 1971 in 21 Ländern ${ }^{56}$. Allerdings bleibt - vgl. den Fall KNP - ihre Effizienz im Verhältnis zu den Kosten nicht unbefragt, und besonders in den Ländern der Dritten Welt (z. B. DIA, Zaire); ist ihre Existenz gefährdet.

\section{Hörfunk und Fernseben unter den Bedingungen von Kommerz bzw. öffentlicher Kontrolle}

Seitdem der Rundfunk ab 1922 zum öffentlichen Medium wurde, haben sich drei Organisationsformen herausgebildet: Rundfunk als Staatsbetrieb, Rundfunk als 
öffentlich-rechtliche Anstalt und Rundfunk als privatwirtschaftliches Unternehmen, das seine Sendezeit teilweise an Dritte verkauft und aus dem Erlös nicht nur Subsistenz, sondern auch Gewinn zieht. Die beiden ersten Organisationsformen beruhen (vorwiegend) auf der Finanzierung durch Teilnehmergebühren und sind durch das Merkmal der öffentlichen Kontrolle (teils direkt durch den Staat, teils durch besondere gesellschaftliche Kontrollgremien, z. B. in Deutschland die "Rundfunkräte", in Osterreich das "Kuratorium" des ORF) gekennzeichnet.

Je nach der "Rundfunkverfassung “ eines Landes hat die Kirche, verschieden günstige Chancen, sich am Rundfunk (Hörfunk und Fernsehen) zu beteiligen bzw. wenigstens auf ihn einzuwirken. Lediglich Staatsrundfunksysteme in grundsätzlich kirchenfeindlichen Ländern schließen die Mitwirkung der Kirche gänzlich aus.

Die Gesamtentwicklung international vergleichend zu schildern, ist angesichts der gebotenen Kürze unmöglich. Generell kann man sagen, daß die Kirche alle Arten der sich bietenden Möglichkeiten genutzt, oft jedoch keineswegs ausgeschöpft hat. Das privatwirtschaftliche Modell bietet in jenen Ländern, wo es praktiziert wird, vornehmlich also in den USA und in den von den USA beeinflußten Ländern Lateinamerikas und Asiens, zwei Chancen: a) den Kauf von Sendezeit für kirchliche Sendungen (praktiziert z. B. in den USA und in Japan), b) die Errichtung eigener Sendeanstalten, denn die hier gemeinten Länder verfahren in der Erteilung von Rundfunkkonzessionen eher liberal. Der Weg,$b^{c}$ wurde allerdings mit Erfolg vornehmlich von internationalen protestantischen Trägern beschritten: So entstanden u. a. die "Stimme der Anden " in Quito (bereits 1931), die "Stimme des Evangeliums" (Radio Voice of the Gospel, 1963, Addis Abeba), die „Far East Broadcasting Company" (gegründet 1945, Sitz in Whittier, Cal., Asien-Hauptsitz seit 1948 in Manila) und "Trans World Radio" (Monte Carlo, 1954 gegr. als Voice of Tanger), das seit 1959 als "Evangeliumsrundfunk * eine deutsche Niederlassung in Wetzlar unterhält $t^{57}$. Auf katholischer Seite vergleichbar wären das mit deutscher Hilfe in Manila/ Quezon City gegründete Unternehmen „Radio Veritas“, das 1968 seinen Betrieb aufnahm und mit mannigfachen Startschwierigkeiten zu kämpfen hatte, sowie die ebenfalls auf den Philippinen (Sitz Manila) tätige Federation of Catholic Broadcasters. In Ländern mit öffentlich-rechtlichen (oder ähnlichen) Rundfunksystemen nimmt die Kirche im Rahmen der gesetzlichen Möglichkeiten einerseits an der gesellschaftlichen Kontrolle der Rundfunkanstalten (z. B. durch Rundfunkräte) teil, andererseits nutzt sie die Möglichkeiten, eigene Verkündigungssendungen (z. B. Gottesdienstübertragungen) zu gestalten und an den Sendungen der für Kirche und Religion zuständigen Abteilungen gestaltend oder beratend mitzuwirken. Klar ausgeprägt haben sich diese Kompetenzzuteilungen besonders in der Bundesrepublik Deutschland, wo in den ersten Jahren nach dem $Z$ weiten Weltkrieg das Projekt eines eigenen christlichen „Bamberger Senders ${ }^{\alpha}$ scheiterte $^{58}$, und in Osterreich. Durchaus eine Sonderform hat, im Zuge der weltanschaulichen „Versäulung ${ }^{\alpha}$, das Rundfunkwesen der Niederlande entwickelt: Während die Nederlandse Omroep Stichting Träger des Gesamtrundfunks ist, wird das Programm durch mehrere, meist weltanschaulich orientierte Betriebsunternehmen besorgt, deren Position von der Zahl der sich zu ihnen bekennenden Teilnehmer abhängt. Seit 1925 beschickt der Katholieke Radio Omroep (KRO, Hilversum) den katholischen Part ${ }^{50}$.

Während ausländische Beobachter das niederländische System nicht selten als die ideale Verwirklichung pluralistischer Rundfunkarbeit ansehen, gibt es in den Niederlanden auch zahlreiche kritische Stimmen. 
1931 errichtete der Vatikan unter dem Namen Radio Vatikan eine eigene Rundfunkstation; sie arbeitete sendetechnisch zunächst mit sehr bescheidenen Mitteln. Nach dem Ausbau (1952-1957) auf einem Gelände außerhalb des Vatikanstaates $25 \mathrm{~km}$ nördlich von Rom (Sta. Maria in Galeria) strahlt Radio Vatikan Hörfunksendungen auf Mittel-, Kurz- und Ultrakurzwelle in etwa 30 Sprachen in alle Welt aus ${ }^{80}$.

\section{Kirchliche Publizistik in der Dritten Welt}

In vielen Ländern der Dritten Welt ruht die kirchliche Publizistik der Gegenwart auf Fundamenten, die in der Kolonialzeit durch missionarische Arbeit gelegt wurden. Dabei sind zwei verschiedene Schwerpunkte erkennbar: In manchen Ländern Asiens, besonders aber in Afrika, wurde früh mit christlicher Pressearbeit begonnen; in Lateinamerika hingegen entwickelte sich aus bescheidenen Anfängen ein fruchtbares Feld katholischer Rundfunkarbeit insbesondere im Bereich des Erziehungs- und Bildungsrundfunks. Katholische "Radioschulen " und vergleichbare Einrichtungen bzw. Programmangebote entstanden nach dem Zweiten Weltkrieg u. a. in Bolivien, Brasilien, Chile, der Dominikanischen Republik, in Ekuador, Kolumbien und Peru. Katholische Sender waren dabei nicht allein auf den Lehrzweck ausgerichtet, sondern entfalteten vornehmlich der Landbevölkerung dienende Systeme gesellschaftlicher Kommunikation, in denen zu Hörfunkprogrammen und Schulungskursen gelegentlich auch zeitungsähnliche Informationsblätter hinzutraten, so im international bekanntesten Radioschulprojekt, Radio Sutatenza in Kolumbien, die Wochenzeitung „El Campesino" mit einer Auflage von 70.000. Das seit 1949 von der Acción Cultural Popular (ACPO) getragene Unternehmen, gegründet 1947 von dem Kaplan José Joaquin Salcedo, konnte die Analphabetanzahl Kolumbiens erheblich senken und wichtige Beiträge zur Dorfentwicklung leisten ${ }^{61}$.

Oberhaupt ist die kirchliche Publizistik in der Dritten Welt im Jahrzehnt nach 1960 immer stärker unter den Gedanken der Entwicklungsförderung gestellt worden ${ }^{62}$. Dies ist ein neuer Akzent gegenüber der missionarischen und pastoralen Motivation, welche Jahrzehnte lang die katholische Pressearbeit in vielen afrikanischen und in einigen asiatischen Ländern (z. B. Indien) bestimmte. Je mehr afrikanische Staaten unabhängig wurden, desto häufiger gerieten katholische Zeitungen und Zeitschriften in schwierige Situationen: Einerseits waren sie politisch weniger belastete Träger eines publizistischen Expertenwissens, das in vielen der jungen Staaten fehlt, andererseits gerieten sie in Konflikte mit politisch einseitigen Systemen, aber auch in wirtschaftliche Schwierigkeiten, welche die Union Catholique Internationale de la Presse besorgt fragen ließen: "La presse catholique d'Afrique est-elle condamnée? ${ }^{\alpha \theta 3}$ Zahlreiche traditionsreiche katholische Blätter, darunter die katholische Tageszeitung "Munno" (gegründet 1911, Kampala, Uganda, 1976 verboten), die Wochenblätter "Afrique Chrétienne (1961, Kinshasa, Zaire), "Afrique Nouvelle" (1947, Dakar, Senegal, 1972 eingestellt, 1974 wiederbelebt), "L'Effort Camerounais" (1955, Yaounde, Kamerun, 1975 eingestellt), „La Croix du Dahomey“ (1946, Cotonou, Dahomey) oder "The Standard“ (1939, Cape Coast, Ghana, seit 1976 Accra) mußten ihr Erscheinen zeitweilig oder ganz einstellen; andere wie "Kiongozi“ (1950, Dar es Salaam, Tansania) blieben lebenskräftig. Politische Verbote oder Behinderungen kamen aus ganz verschiedenen Richtungen: in Zaire wurde 1973 die ganze katholische Presse suspendiert, im ,weißen' Rhodesien konzentrierte sich die kritische Aufmerksamkeit der Regierung auf die Produkte des katholischen Verlages Mambo Press (Gwelo). 
Trotz mannigfacher Gefährdungen und wirtschaftlicher Engpässe besteht in Afrika und Asien eine katholische Presse in bescheidenen Dimensionen, aber doch erstaunlicher Vielfalt ${ }^{64}$. Dabei haben die Gründer und Redakteure, meist Angehörige von Missionsorden oder -genossenschaften, früh versucht, Veröffentlichungen in den Landessprachen zu publizieren. Dies gilt auch für die publizistische Erschließung sehr entlegener Gebiete z. B. Ozeaniens und selbstverständlich generell für die Rundfunkarbeit in allen Missionsgebieten ${ }^{65}$.

Verständnis für die Probleme der Mission (und heute der Entwicklungsländer) zu fördern, hat sich die in den USA und vielen Ländern Europas recht stark entwickelte Missionspresse zum Ziel gesetzt ${ }^{68}$. Ihre Anfänge, in Deutschland markiert durch die Gründung der Zeitschrift „Die katholischen Missionen“ (1873), reichen in das 19. Jahrhundert zurück. Lange Zeit waren die populären Zeitschriften willkommener Lesestoff als Gegenwert für das Opfer zugunsten der Mission. Das veränderte Verhältnis zur Dritten Welt (Entwicklungshilfe, Strukturförderung, die neuen Hilfswerke, ,Misereor', ,Adveniat' etc.) ließ das Interesse an der klassischen Missionspublizistik zurückgehen; die Auflagen vieler Blätter schrumpften, und es entstand, hervorgegangen aus den ersten freiwillig initiierten Konzentrationsvorgängen auf dem katholischen Pressemarkt, ein neuer Typ von Missionsmagazinen, die jeweils von mehreren in der Mission tätigen Religiosengemeinschaften gemeinsam herausgegeben werden: in Deutschland "Kontinente" (seit 1966, anfangs 12, später 25 Träger), in den Niederlanden "Bijeen" (1968, 17 Träger) in Spanien "Tercer Mundo" (1970, 6 Träger), in Frankreich - wenig erfolgreich - „Peuples du Monde ${ }^{\alpha}(1965)^{67}$. Daneben konnten sich weiterhin einige, zum Teil auflagenstarke, Einzeltitel halten, deren Standfestigkeit auf der Kombination zwischen unterhaltsamem Familienblatt und Missionszweck beruht.

\section{Kirche und Massenkommunikation in Theorie und Organisation}

Das seit der Reformation eher negative Verhältnis der Kirche zur Medienpublizistik hat schon im 19., besonders aber im 20. Jahrhundert eine große Zahl päpstlicher und bischöflicher Stellungnahmen provoziert, deren Grundtenor verdammend bis ablehnend, nur gelegentlich die "gute" (katholische) Presse ermunternd war. Sie füllen inzwischen eigene, fachlich spezialisierte Quellensammlungen ${ }^{88}$. Eine Wende bahnte sich mit der ersten eigentlichen Massenmedien-Enzyklika, der Film-Enzyklika „Vigilanti cura ${ }^{4}$ Pius XI., an (1936) ${ }^{68}$. Inhaltlich führte dieses Rundschreiben verbindliche Kontrollinstitutionen ein: Nach dem Muster der amerikanischen Legion of Decency entstanden in vielen Ländern katholische Filmbeurteilungsstellen, so nach dem Zweiten Weltkrieg in Deutschland, Osterreich und der Schweiz Katholische Filmkommissionen, deren Tätigkeit in ihrer informativen Komponente sehr segensreich war, in ihrer moralisch-steuernden Absicht jedoch inzwischen überholt ist ${ }^{70}$. Die Schrittmacher-

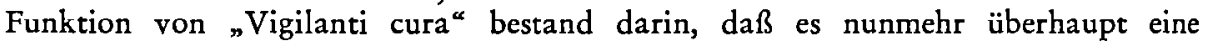
Medien-Enzyklika gab. Ihr folgten 1957 „Miranda prorsus“, eine weitere Enzyklika, die sich mit den audiovisuellen Medien befaßte ${ }^{71}$, und 1963 das dürftige Dekret "Inter mirifica" des Zweiten Vaticanums ${ }^{72}$. Wirkliche Fortschritte in der - im eigentlichen Sinne - theoretischen Auseinandersetzung der Kirche mit den Massenmedien brachte eine Ansprache Pius' XII., 1950 gerichtet an den III. Internationalen Kongreß der katholischen Presse in Rom ${ }^{73}$, und die durch das erwähnte Konzilsdekret veranlaßte, erst 1971 fertiggestellte Pastoralinstruktion "Communio et Progressio ${ }^{\alpha 74}$. Pius XII. erkannte und beschrieb die Massenkommunikation als gesell- 
schaftliche Funktion, indem er die öffentliche Meinung („natürliches Echo", "gemeinsamer Widerhall") als naturrechtlich unabdingbar für das Funktionieren der Gesellschaft darstellte. Leider blieb dann das vornehmlich das Recht der Kirche auf Besitz und Nutzung von Massenmedien sowie die (moralisch) „rechte Benutzung dieser Werkzeuge" betonende "Inter mirifica"-Dekret „hinter der von Pius XII. entwickelten Lehre erheblich zurück ${ }^{475}$. "Communio et Progressio" hingegen verarbeitete nicht nur wichtige Ergebnisse der modernen Publizistik- und Kommunikationswissenschaft, sondern stellte auch allgemein gesellschaftlich relevante Leitgedanken vor: die Funktion der Medien als Vermittlungseinrichtungen, welche "die Zeitgenossen sozusagen um einen runden Tisch" versammeln, das Recht auf Information und freie Informationsauswahl, die Kommunikationsfreiheit, die Notwendigkeit der Medienpädagogik (statt Zensuren und Verbotskatalogen), die Anerkennung der Eigengesetzlichkeit journalistischer Arbeit, den Anspruch katholischer Journalisten, Kommunikationseinrichtungen und des katholischen Publikums auf helfende Partnerschaft der Kirche. Ohne daß auf Maßstäbe (Gemeinwohl, Menschenwürde, Sachgerechtigkeit) verzichtet würde, wird doch die Abkehr vom "Prinzip Abwehr"78 und von der moralisierenden Unterscheidung $\mathrm{z}$ wischen "guter" und „schlechter" Presse wohltuend deutlich.

Die Instruktion weist ferner indirekt, durch Vorschläge, auf die Mangelhaftigkeit publizistischer Organisation hin, wie sie in den Kirchen vieler Länder festzustellen ist. Umfassende Aufgaben werden den bereits bestehenden internationalen PublizistikVereinigungen zugewiesen, während in Wirklichkeit diese Organisationen trotz historischer und völkerverbindender Verdienste heute selbst ihren engsten Aufgabenstellungen oft nur mit Mühe gerecht werden können. Es handelt sich dabei um die 1935 (Vorläufer 1923) gegründete Union Catholique Internationale de la Presse (UCIP), die aus dem 1928 gegründeten Bureau International de la Radiophonie Catholique hervorgegangene "Unda" (Association Catholique Internationale pour la Radiodiffusion et la Télévision) und das Office Catholique International du Cinéma $(\mathrm{OCIC})^{77}$. Die UCIP, fachlich in fünf Föderationen (Zeitungs- und Zeitschriftenverleger, Nachrichtenagenturen, Journalisten, Publizistikwissenschaft und Kirchenpresse), regional in einige kontinentale Unterverbände gegliedert, international repräsentativ in Erscheinung tretend mit Weltkongressen der katholischen Presse, sieht ihr generelles Ziel in der Förderung, Ordnung und Vertretung der Arbeit der katholischen Journalisten und Presseverbände auf internationaler Ebene, speziell in den Tätigkeitsbereidhen Berufsethik und Theologie der Massenkommunikation, Förderung der katholischen Publizistik in Entwicklungsländern und Vertretung bei internationalen Organisationen (UNO, UNESCO). Die Unda, die wesentliche Impulse dem ersten und zweiten Internationalen Katholischen Rundfunkkongreß (München 1929, Prag 1936) verdankt, hat ebenfalls kontinentale Untergruppen in Südamerika, Asien und Afrika aufgebaut und pflegt die internationale Zusammenarbeit ebenso wie die interkonfessionelle mit der World Association for Christian Communication (WACC). Unda wie OCIC vergeben internationale Funk- bzw. Filmpreise. Die Hauptaufgaben des OCIC liegen in der Zusammenarbeit der etwa 50 nationalen katholischen Filmbüros, im Studium von Filmkunst und -wirtschaft nach christlichen Wertkategorien, in der Initiierung neuer katholischer Filmbewegungen und im Einsatz für den künstlerisch und erzieherisch wertvollen Film.

Für neue internationale Aufgaben, nämlich die beratende Förderung der katholischen Publizistik in Entwicklungsländern, wurde auf der Basis der Zusammenarbeit von UCIP, Unda und OCIC 1969 in Aachen das Catholic Media Council (Publizi- 
stische Medienplanung für Entwicklungsländer e. V.) gegründet. Seine Aufgaben sind der internationale Erfahrungsaustausch, die Planungskoordinierung und -beratung, die Auswertung wissenschaftlicher Ergebnisse und nicht zuletzt die fachliche Vorprüfung konkreter Förderungsprojekte. Die auch publizistische Projekte unterstuitzenden katholischen Hilfs- und Missionswerke sind im Kuratorium vertreten ${ }^{78}$. Das $\mathrm{CaMeCo}$ bearbeitet und berät Projekte, die z. B. von Hilfswerken Belgiens, der Niederlande, Osterreichs, der Schweiz, Englands, Irlands, der USA und Deutschlands gefördert werden.

Schlußbemerkung: Der beträchtliche theologische, organisatorische, ökonomische und journalistische Aufwand, mit dem katholische Publizistik nach wie vor betrieben wird, und auch die (relativ spät einsetzende) positive lehr- und hirtenamtliche Aufmerksamkeit für Probleme der Massenkommunikation, können nicht darüber hinwegtäuschen, daß spätestens seit dem Zweiten Vaticanum auf Seiten des „katholischen Publikums" ein auffälliger Integrationsschwund ${ }^{79} \mathrm{zu}$ beobachten ist, und $\mathrm{zwar}$ besonders in den "starken " katholischen Publizistik-Ländern, in denen katholische Medien nicht traditionell-konventionell bleiben können, sondern sich gegenüber nichtkatholischen Bevölkerungsgruppen ständig profilieren müssen, besonders deutlich also in den USA, den Niederlanden, der Schweiz, der Bundesrepublik Deutschland, aber auch in Osterreich. Die Tatsache, daß sich ein wachsender Teil des potentiellen katholischen Publikums der spezifisch katholischen Publizistik entzieht, und die gesicherte Beobachtung, daß dieser Vorgang quantitativ ähnlich verläuft wie der Rückgang der Kirchenbesucherzahlen $^{80}$, wird möglicherweise einmal der charakteristische Grundzug katholischer Publizistikgeschichte der zweiten Hälfte des 20. Jahrhunderts sein. Dokumente einiger nachkonziliarer Synoden haben dieser Entwicklung wenigstens ansatzweise Rechnung zu tragen versucht ${ }^{81}$.

\section{Anmerkungen:}

1. Vgl. etwa (wenngleich veraltet) L. Bethleem: La Presse, Paris 1928; ferner (um der zeitgenössischen Quellen willen) R. Pesch: Die kirchlich-politische Presse der Katholiken in der Rheinprovinz vor 1848, Mainz 1966; M. Schmolke: Die schlechte Presse. Katholiken und Publizistik zwischen "Katholik" und „Publik“ 1821-1968, Münster 1971, sowie für die protestantische Seite (trotz des irreführenden Titels) K. W. Bühler: Presse und Protestantismus in der Weimarer Republik, Witten 1970.

2. Publizistik wird als Oberbegriff für jegliche öffentliche und aktuelle gesellschaftliche Kommunikation verwendet, also auch für deren vor-technische Erscheinungsformen; von Massenkommunikation ist tunlich nur dann die Rede, wenn gesellschaftliche Kommunikation mit Hilfe der modernen, technisch bedingten Medien (Presse, Film, Hörfunk und Fernsehen) bewirkt wird.

3. J. Lukas: Die Presse, ein Stück moderner Versimpelung, Regensburg 1867, S. 116: „Die Presse, wie sie sich heute ausgewachsen hat, ist ein großes Ubel; unsere katholische Presse ist etwas Gutes, weil sie das kleinere Übel ist."

4. Vgl. M. Schmolke: Zur Gliederung der katholischen Pressegeschichte Deutschlands, in: "Communicatio Socialis“ (=CS), 3 (1970), S. 311-327.

5. Vgl. K. Nüßler: Geschichte des Katholischen Preßvereins für Bayern, Diss. München 1954, R. Kohlbach: Kreuz und Feder, Graz 1933; K. M. Stepan: Stückwerk im Spiegel, Graz und Wien 1949.

6. W. B. Lerg: Die Anfänge der Zeitung für alle, in: W. B. Lerg und M. Schmolke (Hrsg.): Massenpresse und Volkszeitung, Assen 1968, S. 1-46.

7. J. Eberle: Großmacht Presse. Enthüllungen für Zeitungsgläubige, Forderungen für Männer, Mergentheim ${ }^{1} 1912$, Regensburg u. Wien ${ }^{3} 1920$. 
8. G. Chiaudano: Il giornalismo cattolico, Turin ${ }^{1} 1910$, dt.: Die katholische Schriftstellerei, Freiburg/Ue. 1911.

9. Vgl. dazu E. Ritter: Die katholisch-soziale Bewegung Deutschlands im neunzehnten Jahrhundert und der Volksverein, Köln 1954, S. 277. - Einen Oberblick über katholische Bemühungen um den Film kurz nach dem Ersten Weltkrieg gibt eine "Kino-Nummer" des „Augustinus-Blatts“ 26 (1922): Nr. 5/6.

10. Zu diesem Themenbereich G. Bauer: Kirchliche Rundfunkarbeit 1924-1939, Frankfurt/ Main 1966.

11. Bericht vom Essener Katholikentag 1932, S. 241.

12. Zeitgenössische Quelle: G. Ernst und B. Marschall (Hrsg.): Film und Rundfunk. Zweiter Internationaler Katholischer Filnkongreß, Erster Internationaler Katholischer Rundfunkkongreß. Gesamtbericht, München 1929.

13. Zur Ausarbeitung eines normierenden "Production Codes“ (auch "Hays Moral Code 1929/1931, erneuert 1939) wurde ein Jesuitenpater, Daniel Lord, herangezogen. V. Engelhardt: Kirche und Film, Düsseldorf 1958, S. 42 ff.; U. Gregor und E. Patalas: Geschichte des Films. München 1973, S. 205 f.

14. Vgl. C. Ford: Le Cinéma au service de la foi, Paris 1953; dt. (bearbeitet:) Der Film und der Glaube, Nürnberg 1955.

15. M. Schmolke: Die schlechte Presse, a.a.O., S. 28 f.

16. W. Kisky (Hrsg.): Der Augustinus-Verein zur Pflege der katholischen Presse von 1878 bis 1928, Düsseldorf 1928, S. 227 und 229.

17. H. Kapfinger: Die Struktur der katholischen Presse, in: J. W. Naumann (Hrsg.): Die Presse und der Katholik, Augsburg 1932, S. 211-228.

18. Einen Uberblick versucht O. Groth: Die Zeitung, Bd. II, Mannheim, Berlin, Leipzig 1929, S. 436-438. Zu den statistischen Quellen führen in M. Schmolke: Die schlechte Presse, a.a.O., Literaturverzeidhnis S. 395-416, u. a. folgende Literaturhinweise: $K$. Bringmann, J. Frizenschaf 1888, M. Grünbeck, F. Hülskamp 1875, H. Keiter 1895 und 1913, W. Kisky, K. Löffler 1924; ferner die Pressestatistiken von L. Woerl, die bei M. Schmolke, a.a.O., S. 372, Anm. 147, bibliographiert sind.

19. "Rede des Reichsministers Dr. Goebbels vor der deutschen Presse bei Verkündigung des Schriftleitergesetzes am 4. Oktober 1933", zit. nach dem Abdruck bei H. Schmidt-Leonhardt und P. Gast: Das Schriftleitergesetz vom 4. Oktober 1933, Berlin ${ }^{3} 1944$, S. 9-22, hier 14.

20. S. Kessemeier: Katholische Publizistik im NS-Staat 1933-1938, Münster 1973, S. 18 f.

21. Zur "Kölnischen Volkszeitung" und "Germania" vgl. die einschlägigen Aufsätze von R. Kramer bzw. K. M. Stiegler in: H. D. Fischer (Hrsg.): Deutsche Zeitungen des 17. bis 20. Jahrhunderts, Pullach 1972. - Die Geschichtsschreibung der katholischen Presse im Dritten Reich wird neuerdings durch die (im Titel untertreibende) Dissertation von M. Hüsgen (Die Bistumsblätter in Niedersachsen während der nationalsozialistischen Zeit, Hildesheim 1975) ergänzt und im ganzen auf eine solidere Basis gestellt.

22. Vgl. Kessemeier, a.a.O., S. 20 ff.

23. Zur Statistik vgl. K. A. Altmeyer: Katholische Presse unter NS-Diktatur, Berlin 1962, S. 79 und 94-98. - Zur tatsächlichen Lage bei den "Bistumsblättern" (eines oder mehrere pro Diözese?) M. Hüsgen, a.a.O., S. 120-123.

24. Istituto Cattolico per la Stampa (Hrsg.): La Stampa Cattolica nel Mondo, Mailand 1939.

25. F. Funder: Vom Gestern ins Heute, Wien 1952. Vgl. ferner R. Barta: Katholische Pressearbeit in Osterreich, in: K. Richter (Hrsg.): Katholische Presse in Europa, Osnabrüdk 1969, S. 43-62.

26. F. P. Schaller: Notstand im christlichen Pressewesen; Zürich 1974, S. 154 f. Zur Situation in der Schweiz vgl. auch C. Holenstein: Katholische Presse in der Schweiz, in: K. Richter, a.a.O., S. 63-70, ferner E. Fehr: Schweiz: Katholische Presse in der Krise, in: CS 8(1975), S. 150-152.

27. Vgl. Handbudh der Kirchengeschichte, Bd. VI/1, S. 473 ff.

28. J. et Ph. Godfrin: Une Centrale de la Presse Catholique: La Maison de la Bonne Presse et ses Publications, Paris 1965, S. 134. 
29. Ch. Ehlinger: Katholische Presse in Frankreich, in: K. Richter, a.a.O., S. 95-115; vgl. auch G. Hourdin: La Presse Catholique, Paris 1957.

30. Ehlinger, a.a.O., S. 111.

31. A. Montero: Kirche, Katholiken und Presse in Spanien, in: K. Richter, a.a.O., S. 116142, hier S. 122.

32. Vgl. J. Liminski: Journalistenausbildung an der katholischen Universität von Navarra in Pamplona, in: CS 8(1975), S. 153-164.

33. D. Hansche: Zur Geschichte des „L'Osservatore Romano“, in: CS 3(1970), S. 13-23 und 99-109, hier S. 13 f. (Bei Itansche auch die einschlägige Literatur zur Geschichte des OR.)

34. Vgl. Hansche, a.a.O., S. 100.

35. Zit. bei Hansche, a.a.O., S. 101.

36. I. Weiß: Il potere di carta. Il giornalismo ieri ed oggi, Turin 1965, S. 107, zit. nach Hansche, a.a.O., S. 103.

37. Vgl. H. D. Fischer: Die großen Zeitungen, München 1966, S. 294.

38. E. Bordfeld: Der „Osservatore Romano“ - Wochenausgabe in deutscher Sprache, in: CS 7(1974), S. 155-159, sowie G. Deussen: Der deutschsprachige „Osservatore Romano" " überflüssig? in: CS 5(1972), S. 343-345.

39. Vgl. D. Hansche: Krise und Ende des „L'Avvenire d'Italia“, in: CS 3(1970), S. 348一351.

40. Vgl. das Annuario 1970 der Unione Cattolica Stampa Italiana (UCSI), Rom 1970, P. VI: La stampa cattolica in Italia, S. 491-556. - Jüngste Auskunft über die katholische Presse Italiens gibt die Meldung Nr. 2094 im KNA-Informationsdienst Nr. 40/1976 vom 30. 9. 1976, S. 4: Italiens Kirchenpresse: eine aufschlußreiche Statistik.

41. E. Bordfeld: 40 Jahre ${ }_{n}$ Famiglia Cristiana", in: CS 4(1971), S. 126-128.

42. G. W. Marsman: De Katholieke Dagbladpers in sociologisch perspectief, Assen 1967. Derselbe: Katholische Presse in den Niederlanden, in: K. Richter, a.a.O., S. 71-81.

43. J. Hemels: Katholische Presse in den Niederlanden, in: CS 8(1975). Teil I: S. 1-22. Teil II: S. 123-146. - Für Skandinavien vgl. J. Berg: Skandinavien: Die katholische Presse, in: „UCIP Informations“, Genf, Nr. 4/1976, S. 8 f.

44. L. Boone: Situation und Zukunftstendenzen der katholischen Presse in Belgien: in: K. Richter, a.a.O., S. 95-115.

45. J. Gelamur: Luxemburger Wort, in: „Journalistes Catholiques“, Genf, 21(1973), SpezialDoppelnummer, S. 33-35.

46. Vgl. dazu Schmolke: Die schlechte Presse, a.a.O., S. 268.

47. M. Schmolke (Hrsg.): „Publik" - Episode oder Lehrstück? Paderborn 1974. - Zum verlagswirtschaftlichen Aspekt: U. Nussberger: „Publik“ als Testfall verlagswirtschaftlicher Planung, in: CS 9(1976), S. 126-142.

48. F. Oertel: Dialogforum Kirchenpresse, Limburg/L. 1972.

49. J. Hoeren: Die katholische Jugendpresse 1945-1970, Münster 1974 (nicht im Buchhandel; Deutsches Institut für wissenschaftliche Pädagogik, D. I. P.-Information Nr. 8). Zur Entwicklung der katholischen Jugendpresse in Osterreich: H. Pürer: Kirchliche Jugendpublizistik in Osterreich, in: CS 7(1974), S. 137-152.

50. Ein ähnlicher negativer Trend zeichnet sich in der katholischen Presse der USA und Kanada ab, deren Geschichte noch nicht so untersucht ist, daß sie cinen zusammenfassenden Vergleich vom europäischen Standpunkt aus erlaubte. Das überaus vielfältige, zum großen Teil diözesan orientierte Zeitschriftenwesen stellt insgesamt innerhalb der katholischen Presse der Welt den größten Auflagenblock dar. Allerdings schrumpfte or von 27,7 Millionen im Jahre 1968 auf 22,7 Millionen im Jahre 1973. Unter den mehr als 400 Titeln sind ca. 120 Bistumsblätter. Die Jesuiten-Zeitschrift „America“ (New York, gegründet 1909) dürfte das national und international bekannteste Blatt sein. Der Verband der katholischen Publizistik in den USA, die Catholic Press Association (CPA), arbeitet international mit der deutschen AKP zusammen. - Hinweise auf die Krise bei P. Jordan: „NC News Service“ in der Krise der katholischen USA-Presse, in: CS 3(1970), S. $257-262$.

51. M. Bornefeld-Ettmann: Die Centrums-Parlaments-Correspondenz (CPC), in: CS 1(1968), S. $318-325$. 
52. P. Jordan: "NC-News-Service" in der Krise der katholischen USA-Presse, in: CS 3(1970), S. $257-262$.

53. Katholische Nachrichten-Agentur (Hrsg.): De instrumentis informationis, Bonn 21972.

54. Das KNP mußte seine Tätigkeit 1973 einstellen. Vgl. F. Oudejans: Geschichte und Ende des "Katholiek Nederlands Persbureau" (KNP), in: CS 6(1973), S. 144-151.

55. J. J. Considine: Die Gründung des internationalen Fides-Dienstes, in: CS 5(1972), S. 5356.

56. Für 1936: La Stampa Cattolica nel Mondo, a.a.O., S. 36. Für 1971: „Journalistes Catholiques ${ }^{\star}$, Paris, 19(1971), Nr. 56/57, S. 9.

57. K. H. Hochwald: Trans World Radio und Evangeliums-Rundfunk, in: CS 2(1969), S. 56-58. - Ch. Jahn: Frequenzen der guten Nachricht. Rundfunksender „Stimme des Evangeliums" Addis Abeba, Erlangen 1973. G. H. Ledyard: Sky Waves. The Incredible Far East Broadcasting Company, Chicago 1963. Zusammenfassend: J. Schmidt: Massenmedien als Instrumente der Mission. Missionsrundfunk als Beispiel, Diss. Heidelberg 1974. - Neu ist der Versuch eines katholischen Diözesan-Fernsehens in Chicago; vgl. F. J. Eilers: ctn-Diözesan-Fernsehen in Chicago, in: CS 9(1976), S. 39-41.

58. Vgl. M. Schmolke: Die schlechte Presse, a.a.O., S. 272 f.

59. J. Hemels: Der katholische Rundfunk im niederländischen Rundfunksystem, in: CS $8(1975)$, S. $213-229$.

60. E. Schmitz: Sender des Friedens, in: K. Becker und K.-A. Siegel (Hrsg.): Rundfunk und Fernsehen im Blick der Kirche, Frankfurt/M. 1957, S. 32-40, und A. Kochs: Radio Vatikan, in: „Funk-Korrespondenz“, 23(1975), Nr. 4, S. 1-4 und Nr. 5, S. 5-8.

61. St. A. Musto: Massenmedien als Instrumente der ländlichen Entwicklungsförderung, Berlin 1969.

62. Vgl. die Bibliographie, Church and Communication in Developing Countries" (bearbeitet von W. Herzog), Paderborn 1973, und den Sodepax-Konferenz-Bericht, Churd, Communication, Development', Genf o. J. (1971).

63. Afrika-Hefte Nr. $62 / 63$ und Nr. $64 / 65$ der Zeitschrift ${ }_{n}$ Journalistes Catholiques", Paris, 1972.

64. Vgl. F. J. Eilers und W. Herzog: Catholic Press Directory Africa/Asia, Paderborn 1975; F. J. Eilers: Christliche Publizistik in Afrika, St. Augustin 1964; C. H. M. Verhaak: Aspecten van de pers in Oost-Afrika, Grave 1974; J. Hosse: Die katholische Presse im französischsprachigen West- und Zentralafrika, in: CS 5(1972), S. 156-162; T. Luiz: Indian Catholic Press, Bombay 1971; J. Barret: Katholische Presse in Indien, in: CS 1(1968), S. 43-45.

65. F. J. Eilers: Zur Rolle der Publizistik in der Missionsarbeit des Fernen Ostens und Ozeaniens, Münster 1965; derselbe: Presse und Funk im Territorium von Papua und Neuguinea, in: CS 1(1968), S. 197-208, 295-307.

66. L. Janek: Katholische Missionszeitschriften in den USA, in: CS 4(1971), S. 226-232, J. Simmers: Missionspublizistik in den Niederlanden, in: CS 1(1968), S. 40-43; M. Eigenmann und F. H. Fleck: Schweizer Missionsjournalistik, in: CS 3(1970), S. 339343. F. J. Eilers: Arnold Janssen als Publizist: ein Beitrag zur Geschichte der deutschsprachigen Missionspublizistik, in: CS 8(1975), S. 301-323.

67. J. Hosse: Missionspresse im Wandel der Zeit, in: CS 5(1972), S. 348-351.

68. E. Baragli (Hrsg.): Cinema Cattolico, Rom ${ }^{2} 1965$; Ders.: Comunicazione, Comunione e Chiesa, Rom 1973; Radio Vaticana (Hrsg.): (1) Documenti Pontifici sulla Radio e sulla Televisione (1929-1962), Rom (Vatikan) 1962, (2) Documenti Pontifici sulla Stampa (1878-1963), ebda. 1963, (3) Documenti Pontifici sul Teatro (341-1966), ebda. 1966. Dazu: G. Deussen: Ethik der Massenkommunikation bei Papst Paul VI., Paderborn 1973.

69. AAS XXVIII (1936), S. 249-263.

70. A. Paffenholz: Katholische Filmbewertung in der Diskussion, in: CS 2(1969), S. 5-12.

71, AAS XIIX (1957), S. 765-805.

72. LThK: Das Zweite Vatikanische Konzil, Teil I, Freiburg 1966, S. 116-135.

73. AAS XIII (1950), S. 251-257.

74. Communio et Progressio. Pastoralinstruktion über die Instrumente der sozialen Kommunikation, Rom 1971. 
75. O. B. Roegele: Das Konzilsdekret „Über die Werkzeuge der sozialen Kommunikation“, in: "Publizistik" 9(1964), S. 305-347, hier 319.

76. M. Sdhmolke: Zehn ideengeschichtliche Beobachtungen zur Pastoralinstruktion "Communio et Progressio", in: F. J. Eilers u. a. (Hrsg.): Kirche und Publizistik. Dreizehn Kommentare zur Pastoralinstruktion ..., Paderborn 1972.

77. J. Iribarren: L'Union Catholique Internationale de la Presse (UCIP), in: CS 3(1970), S. 49-55; 1t. „UCIP-Informations“ Nr. 1/1977, S. 2, geht die UCIP auf das „Bureau International des Journalistes Catholiques ${ }^{\alpha}$ zurück, das auf Anregung von René Delforge 1927 in Belgien gegründet worden sei. J. Schneuwly: UNDA - Katholische Internationale Vereinigung für Hörfunk und Fernsehen, ebda. S. 144-151; E. Flippo: Office Catholique International du Cinéma (OCIC), ebda. 4(1971), S. 28-34.

78. K. R. Höller: Publizistische Medienplanung für Entwidklungsländer "Catholic Media Council“, in: CS 5(1972), S. 57-63.

79. Zum Begriff vgl. F. Groner: Integrationsschwund in der katholischen Kirche Deutschlands. In: Jahrbuch für christliche Sozialwissenschaften 12(1971), S. 215-239. Vgl. ferner die Beiträge von H. Fleckenstein und R. Bleistein in: K. Forster (Hrsg.): Befragte Katholiken - Zur Zukunft von Glaube und Kirche, Freiburg/Br. 1973.

80. Vgl. dazu besonders die o. a. Arbeiten von Hemels und Marsman: Daten zum Rückgang im (nichtveröffentlichtem) ,Gutachten Katholische Publizistik 72/73" (Stellungnahme Nr. 7) des Verfassers sowie in den verschiedenen Berichtbänden der (ebenfalls nidhtveröffentlichten) „Feldbefragung ${ }^{\star}$ (Kommunikations- und Informationserwartungen der katholischen Bevölkerung gegenüber kirchlichen Massenmedien, insbesondere der Kirchenpresse). Institut für Kommunikationsforschung, Wuppertal 1975/76.

81. Literaturhinweise bei M. Schmolke: Kirche und gesellschaftliche Kommunikation, in: D. Emeis und B. Sauermost (Hrsg.): Synode - Ende oder Anfang, Düsseldorf 1976, S. 303-315, sowie P. Pawlowsky: Kirche und Massenmedien nach den österreichischen Synoden, in: CS 9(1976), S. 233-254.

\section{S U M M A R Y}

In the twentieth century the Catholic Church had not only to consider the press, but also new forms of mass media such as film, radio and TV. In fact, only then did the era of mass media beginn. The Church could no longer maintain her attitude of resentment or her pose of protecting the faithful. The attempt to create Catholic media (regarded as a "good" brand) alongside the secular media succeeded in only a few countries in the world. In those countries where it had been possible, in the early days, to create a growing Catholic press as well as Catholic-owned film and radio facilities saw a decline in these as a result of the second world war. This decline is not necessarily a negative sign, as it has of ten been related to a new orientation of Catholics in their respective spheres. Thinking in a ghetto mentality decreased. Catholic mass media developed particularly in those countries where the Catholic Church was among the largest denominations, or where Catholics were under some pressure from secularism, as in the USA, Netherlands, France, Germany, Austria and Switzerland. Italy and Spain developed a strong Catholic press, at least as far as figures are concerned. The author deals diefly with these countries. He does, however, add a dapter on Catholic media in developing countries.

\section{RESUME}

Au XXe siècle, l'Eglise catholique ne devait plus seulement s'expliquer avec la presse, mais aussi avec les autres mass media tels que le film, la radio et la télévision. L'Eglise ne pouvait plus maintenir son attitude primitive de refus, ou tout du moins une attitude contraignante de tutelle et de protection du croyant. De même, la tentative de mettre sur pieds, à côté de la presse séculière (film, radio) des (»bonnes «) institutions catholiques ne réussit que dans peu de pays du globe. Dans les peu de pays où on avait tout d'abord réussi à mettre en 
place une presse catholique florissante, mais aussi des aménagements de films et de radio s'annonça un recul, au plus tard après la Seconde Guerre mondiale. Il n'est pas seulement à apprécier de façon négative, car il allait souvent de paire avec une nouvelle orientation des catholiques dans la société. La façon de penser en catégories du guetto catholique fut peu à peu supprimée. Les mass media catholiques s'étaient particulièrement bien développés dans les pays où les catholiques représentent une parmi plusieurs autres confessions ou dans ceux où ils s'opposaient à une forte pression de laïcisme (USA; Pays-Bas, France, Allemagne, Autriche, Suisse). L'Italie et l'Espagne, aussi, développèrent une forte presse catholique, au moins numériquement. Le centre de gravité de la représentation historique repose sur les pays nommés; d'autres ne sont que peu touchés. Un chapître particulier s'applique cependant aux mass media catholiques dans les pays en voie de développement.

\section{RES UME N}

En el siglo XX la Iglesia católica debe confrontarse no sólo con la prensa sino con los nuevos medios de comunicación social: film, radio y televisión. En realidad, comenzó ahora la edad contemporánea de los medios de difusión. La Iglesia no pudo mantener su actitud inicial, contraria 6 cuanto menos centrada en proteger y wconservar« a los fieles. El intento de crear junto a la prensa secular (film, radio) instituciones católicas (mbuenas«), sólo tuvo éxito en pocos países. En algunos países, donde hubo al principio una floreciente prensa católica e incluso propia radio y cinematografía, se produjo un receso lo más tarde después de la Segunda Guerra mundial. El proceso no puede juzgarse sólo negativamente pues a menudo estuvo ligado a una nueva orientación de los católicos en la sociedad. El pensamiento en categorías del Getto católico cedió paulatinamente. - Los medios de difusión católicos se desarrollaron especialmente bien en países en los que los católicos constituyen mayoría con respecto a otras confesiones 6 en los que se encontraban bajo una gran presión "laicista" (USA, Holanda, Francia, Alemania, Austria, Suiza). También en Italia y España se desarrolló una prensa católica poderosa, al menos desde el punto de vista cuantitativo. El quicio del análisis histórico se centra en los palses citados; otros son tratados sólo de pasada. No obstante se dedica capítulo especial a los medios de difusión católicos en los países en desarrollo. 